\title{
DINAMIKA MODEL SUSCEPTIBLE INFECTED RECOVERED (SIR) DENGAN STRATEGI VAKSINASI
}

\author{
NANDA MUTIA UTAMA, ARRIVAL RINCE PUTRI, MAHDHIVAN SYAFWAN \\ Program Studi S1 Matematika, \\ Fakultas Matematika dan Ilmu Pengetahuan Alam, Universitas Andalas, \\ Kampus UNAND Limau Manis Padang, Indonesia. \\ email:mu.nanda21@gmail.com,arrival@sci.unand.ac.id,mahdhivan@sci.unand.ac.id
}

Diterima 15 September 2020 Direvisi 14 Oktober 2020 Dipublikasikan 21 Oktober 2020

\begin{abstract}
Abstrak. Vaksinasi merupakan salah satu cara untuk mencegah sekaligus mengendalikan penyebaran penyakit menular. Penelitian ini membahas salah satu model penyebaran penyakit menular, yaitu model Susceptible Infected Recovered (SIR). Model SIR yang dibahas mempertimbangkan strategi vaksinasi, yaitu vaksinasi konstan dan vaksinasi berkala, yang diberikan kepada individu rentan terinfeksi penyakit. Kajian analitik dilakukan dengan menganalisis kestabilan model di sekitar titik ekuilibrium berdasarkan nilai eigen dari matriks Jacobian. Kestabilan model dikaitkan juga dengan parameter ambang batas, yaitu parameter yang menentukan apakah suatu populasi bebas atau terinfeksi dari penyakit. Simulasi numerik dilakukan untuk mengkonfirmasi hasil analitik dengan menggunakan parameter dari kasus penyakit Tuberkulosis (TBC) di Provinsi Sumatera Barat tahun 2018. Hasil analitik maupun numerik memperlihatkan bahwa pemberian stategi vaksinasi efektif sebagai pencegahan dan pengendalian penyebaran penyakit, sehingga dapat mengurangi jumlah individu yang terinfeksi.
\end{abstract}

Kata Kunci: Model SIR, Vaksinasi, Kestabilan, Parameter Ambang Batas, Simulasi Numerik

\section{Pendahuluan}

Penyakit menular merupakan penyakit yang dapat ditularkan dari makhluk hidup yang sakit ke makluk hidup yang sehat tetapi rentan tertular penyakit tersebut. Dalam mengamati penyebaran penyakit menular secara matematis, digunakan model matematika epidemi, salah satunya Model SIR (Susceptible Infected Recovered) yang ditemukan oleh Kermack dan Mackendrick (1927). Dalam penelitiannya, mereka mengkaitkan dengan penentuan nilai ambang batas atau basic reproduction number (bilangan reproduksi dasar) yang dinotasikan dengan $\mathcal{R}_{0}$.

Dalam dinamika model matematika epidemi akan dilihat bagaimana perilaku model di sekitar titik ekuilibrium. Perilaku ini dianalisis melalui analisis kestabilan yang ditentukan dari nilai eigen matriks Jacobian dari masing-masing titik

*penulis korespondensi 
ekuilibrium. Pada penelitian ini akan dibahas dinamika model SIR dengan strategi vaksinasi. Vaksinasi merupakan salah satu cara untuk mengendalikan penyebaran penyakit menular yang diberikan kepada populasi yang rentan terinfeksi penyakit. Strategi vaksinasi dilakukan dalam dua cara, yaitu vaksinasi yang diberikan secara konstan dan vaksinasi yang diberikan secara berkala kepada individu yang rentan terinfeksi penyakit. Simulasi numerik dilakukan untuk mengkonfirmasi hasil analitik dengan menggunakan parameter dari kasus penyakit Tuberkulosis (TBC) di Provinsi Sumatera Barat tahun 2018.

\section{Landasan Teori}

Pandang sistem autonomous berikut,

$$
\dot{\mathbf{x}}=\mathbf{f}(\mathbf{x}(t)), \quad \mathbf{x}\left(t_{0}\right)=\mathbf{x}_{0}, \quad t \in \mathbb{R} .
$$

\subsection{Kestabilan Sistem Linier}

Definisi 2.1. [7] Titik ekuilibrium (titik kesetimbangan, titik kritis, titik tetap, atau titik stasioner) adalah titik yang memenuhi persamaan $\dot{\boldsymbol{x}}=A \boldsymbol{x}=\boldsymbol{0}$, dengan $A$ adalah matriks koefisien.

Definisi 2.2. [12] Diberikan matriks A berukuran $n \times n$. Suatu vektor tak nol $\boldsymbol{x} \in \mathbb{R}^{n}$ disebut sebagai vektor eigen dari matriks $A$ jika untuk beberapa $\lambda$ (nilai eigen) dari matriks A memenuhi,

$$
A \boldsymbol{x}=\lambda \boldsymbol{x},
$$

dimana $\boldsymbol{x}$ adalah vektor eigen yang bersesuaian dengan nilai eigen $\lambda$.

Definisi 2.3. [8] Solusi dari sistem $\dot{\boldsymbol{x}}=$ Ax dimana $\boldsymbol{x} \in \mathbb{R}^{2}$, ditulis sebagai $\phi(t)=$ $(x(t), y(t))$, merupakan kurva solusi pada bidang xy. Kurva solusi ini disebut dengan trajektori atau orbit.

Definisi 2.4. [8] Potret fase adalah suatu gambar dua dimensi yang memperlihatkan perilaku dari sistem $\dot{\boldsymbol{x}}=$ Ax , ditentukan dari $x$ dan y yang berubah terhadap waktu $t$ dan bergantung pada nilai eigen $\lambda$.

\subsection{Kestabilan Sistem Non-Linier}

Diberikan sistem non-linier autonomous dua dimensi berikut [8]:

$$
\begin{aligned}
& \dot{x}_{1}=f_{1}(x, y), \\
& \dot{x}_{2}=f_{2}(x, y),
\end{aligned}
$$

dimana $f_{1}$ dan $f_{2}$ adalah fungsi dalam variabel $x$ dan $y$ yang minimal berbentuk kuadrat. Analisis kestabilan sistem non-linier dapat didekati secara linier di sekitar titik ekuilibrium menggunakan Matriks Jacobian dalam linierisasi sistem non-linier. 
Definisi 2.5. [5] Misalkan $f: \mathbb{R}^{n} \rightarrow \mathbb{R}^{n}$ adalah fungsi yang dapat diturunkan dan kontinu pada himpunan $D \subset \mathbb{R}^{n}$ dan $x^{*} \in \mathbb{R}^{n}$. Matriks Jacobian di sekitar $x^{*}$, dinotasikan dengan $J$, didefinisikan sebagai

$$
J=\left[\begin{array}{cccc}
\frac{\partial f_{1}}{\partial x_{1}} & \frac{\partial f_{1}}{\partial x_{2}} & \cdots & \frac{\partial f_{1}}{\partial x_{n}} \\
\frac{\partial f_{2}}{\partial x_{1}} & \frac{\partial f_{2}}{\partial x_{2}} & \cdots & \frac{\partial f_{2}}{\partial x_{n}} \\
\vdots & \vdots & \ddots & \vdots \\
\frac{\partial f_{n}}{\partial x_{1}} & \frac{\partial f_{n}}{\partial x_{2}} & \cdots & \frac{\partial f_{n}}{\partial x_{n}}
\end{array}\right]
$$

Setelah dilinierisasikan, sistem (2.3) dapat ditulis menjadi

$$
\dot{\mathbf{y}}=J \mathbf{y}, \mathbf{y} \in \mathbb{R}^{2}
$$

Definisi 2.6. [10] Titik ekuilibrium dari sistem (2.3) disebut titik ekuilibrium hiperbolik jika semua nilai eigen dari matriks Jacobian J mempunyai bagian riilnya bernilai tak nol.

Teorema 2.7. [8] Misalkan (u,v) adalah titik ekuilibrium hiperbolik dari sistem (2.3), Maka terdapat suatu lingkungan dari titik tersebut dimana potret fase untuk sistem non-linier menyerupai sistem linier (2.5).

Teorema 2.8. [5] Pandang sistem (2.5), dimana J matriks Jacobian berukuran $n \times n$ mempunyai $k$ nilai eigen $\lambda_{1}, \lambda_{2}, \cdots, \lambda_{k}$, dengan $k \leq n$.

(1) Jika $\operatorname{Re}\left(\lambda_{i}\right)<0$, untuk $i=1,2, \cdots, n$ maka titik ekuilibirum $\boldsymbol{x}^{*}$ adalah stabil asimtotik.

(2) Jika $\operatorname{Re}\left(\lambda_{i}\right) \leq 0$, untuk $i=1,2, \cdots, n$ maka titik ekuilibirum $\boldsymbol{x}^{*}$ adalah stabil dan untuk nilai eigen $\operatorname{Re}\left(\lambda_{i}\right)=0$ bersesuaian dengan vektor eigen yang bebas linier sebanyak multiplisitas $\lambda_{i}$.

(3) Jika terdapat nilai eigen matriks Jacobian yang mempunyai bagian riil positif, maka titik ekuilibrium $\boldsymbol{x}^{*}$ adalah tidak stabil .

Definisi 2.9. [5] Dua buah sistem persamaan diferensial orde satu autonomous dikatakan ekuivalen kualitatif (topologi) jika terdapat pemetaan yang invertibel dimana salah satu potret fase onto ke potret fase yang lain dengan mempertahankan orbit trajektori.

\section{Model dan Dinamika}

\subsection{Model SIR dengan Strategi Vaksinasi}

Model dikembangkan dengan mengelompokkan individu-individu ke dalam tiga kelompok, yaitu susceptible, infected, dan recovered. Model diformulasikan dengan asumsi sebagai berikut.

(1) Model dikembangkan untuk sistem tertutup (tidak ada proses migrasi).

(2) Jumlah populasi konstan.

(3) Terdapat efek demografi, yaitu kelahiran dan kematian.

(4) Tingkat kelahiran sama dengan tingkat kematian untuk ketiga kelompok. 
(5) Setiap individu yang baru lahir akan langsung masuk ke dalam kelompok rentan.

(6) Populasi bercampur secara homogen. Penyakit menular dapat menyebar melalui kontak langsung antara kelompok rentan dengan kelompok terinfeksi.

(7) Penyebaran penyakit dalam populasi dapat berkurang dengan diberikannya vaksinasi kepada individu baru yang masuk ke dalam kelompok rentan.

Diagram kompartemen untuk model SIR yang memuat vaksinasi digambarkan pada diagram berikut ini.

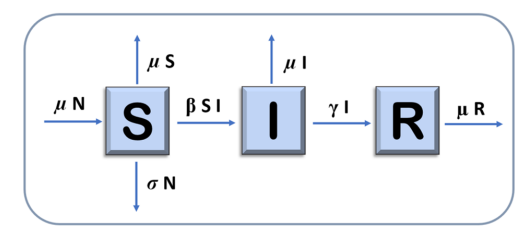

Gambar 1. Diagram Kompartemen Model SIR dengan Vaksinasi

Model SIR dengan vaksinasi konstan dapat dinyatakan sebagai sistem persamaan diferensial biasa,

$$
\begin{aligned}
& \frac{d S}{d t}=(\mu-\sigma) N-\beta I S-\mu S, \\
& \frac{d I}{d t}=\beta I S-\gamma I-\mu I, \\
& \frac{d R}{d t}=\gamma I-\mu R,
\end{aligned}
$$

dengan parameter $\beta, \mu, \sigma, \gamma$ adalah konstanta positif. Deskripsi masing-masing parameter sebegai berikut: $N$ menyatakan jumlah populasi pada suatu wilayah, $S$ meyatakan jumlah individo yang rentan, $I$ menyakan jumlah individu yang terinfeksi, $R$ menyatakan jumlah individu yang sembuh, $\mu$ menyatakan tingkat kelahiran dan kematian, $\gamma$ menyatakan tingkat kesembuhan, $\beta$ menyatakan tingkat penularan, dan $\sigma$ menyatakan tingkat vaksinasi.

Model SIR dengan vaksinasi berkala diformulasikan dengan asumsi yang sama seperti model (3.1), namun pemberian vaksin tidak lagi dilakukan secara konstan, melainkan secara berkala. Model SIR dengan vaksinasi berkala dapat dinyatakan sebagai berikut,

$$
\begin{aligned}
\frac{d S}{d t} & =\left(\mu-\sigma^{*}\right) N-\beta I S-\mu S, \\
\frac{d I}{d t} & =\beta I S-\gamma I-\mu I, \\
\frac{d R}{d t} & =\gamma I-\mu R,
\end{aligned}
$$

dimana didefinisikan sebuah fungsi vaksinasi berkala $\sigma^{*}$ yang diberikan oleh,

$$
\sigma^{*}= \begin{cases}0 & ; \text { jika } \cos (\omega t+\phi) \leq 0, \\ \sigma(\cos (\omega t+\phi)) & ; \text { jika } \cos (\omega t+\phi)>0,\end{cases}
$$


dengan $\omega$ menyatakan periode tahapan dan $\phi$ menyatakan fase tahapan.

\subsection{Analisis Kestabilan Model}

Dalam penelitian ini, akan dibahas analisis kestabilan model $S I R$ dengan vaksinasi konstan. Terdapat dua titik ekuilibrium model (3.1) yang menggambarkan dua keadaan, yaitu: titik ekuilibrium bebas penyakit yaitu $E_{b}=\left(\frac{(\mu-\sigma) N}{\mu}, 0,0\right)$, yang menandakan keadaan bahwa populasi bebas dari penyakit; dan titik ekuilibrium endemik yaitu $E_{b}^{*}=\left(S^{*}, I^{*}, R^{*}\right)=\left(\frac{\gamma+\mu}{\beta}, \frac{(\mu-\sigma) N \beta-\mu(\gamma+\mu)}{\beta(\gamma+\mu)}, \frac{\gamma I^{*}}{\mu}\right)$, yang menandakan keadaan dimana terdapat individu yang terinfeksi dalam populasi. Parameter ambang batas diperoleh berdasarkan titik ekuilibrium endemik $E_{b}^{*}$ dengan mengasumsikan $I^{*}>0$. Didefinisikan $R_{v}=(\mu-\sigma) R_{0}$ adalah paramater ambang batas, dengan $R_{0}=\frac{N \beta}{\mu(\gamma+\mu)}$.

Selanjutnya dengan melinierisasi sistem (3.1) diperoleh Matriks Jacobian

$$
J=\left[\begin{array}{ccc}
-\beta I-\mu & -\beta S & 0 \\
\beta I & \beta S-\gamma-\mu & 0 \\
0 & \gamma & -\mu
\end{array}\right] .
$$

Matriks Jacobian di titik ekuilibrium $E_{b}$ adalah

$$
J_{E_{b}}=\left[\begin{array}{ccc}
-\mu & \frac{-(\mu-\sigma) N \beta}{\mu} & 0 \\
0 & \frac{(\mu-\sigma) N \beta-\mu(\gamma+\mu)}{\mu} & 0 \\
0 & \gamma & -\mu
\end{array}\right]
$$

Matriks Jacobian di titik ekuilibrium $E_{b}^{*}$ adalah

$$
J_{E_{b}^{*}}=\left[\begin{array}{ccc}
\frac{-(\mu-\sigma) N \beta}{(\gamma+\mu)} & -(\gamma+\mu) & 0 \\
\frac{(\mu-\sigma) N \beta-\mu(\gamma+\mu)}{(\gamma+\mu)} & 0 & 0 \\
0 & \gamma & -\mu
\end{array}\right]
$$

Persamaan karakteristik dari Matriks Jacobian $J_{E_{b}}$ adalah

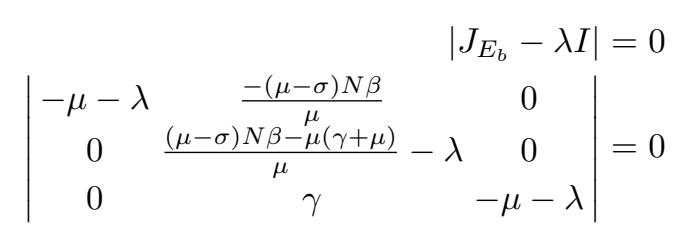

sehingga diperoleh nilai-nilai eigen:

$$
\lambda_{1}=-\mu ; \quad \lambda_{2}=-\mu ; \quad \lambda_{3}=\left(\frac{(\mu-\sigma) N \beta-\mu(\gamma+\mu)}{\mu}\right) .
$$

Sementara itu, persamaan karakteristik dari Matriks Jacobian $E_{b}^{*}$ adalah

$$
\begin{array}{r}
\left|J_{E_{b}^{*}}-\lambda I\right|=0 \\
\left|\begin{array}{ccc}
\frac{-(\mu-\sigma) N \beta}{(\gamma+\mu)}-\lambda & -(\gamma+\mu) & 0 \\
\frac{(\mu-\sigma) N \beta-\mu(\gamma+\mu)}{(\gamma+\mu)} & -\lambda & 0 \\
0 & \gamma & -\mu-\lambda
\end{array}\right|=0
\end{array}
$$


sehingga diperoleh nilai-nilai eigen:

$$
\begin{aligned}
& \lambda_{1}=-\mu \\
& \lambda_{2,3}=\frac{1}{2}\left(\frac{-(\mu-\sigma) N \beta}{(\gamma+\mu)} \pm \sqrt{\left(\frac{(\mu-\sigma) N \beta}{(\gamma+\mu)}\right)^{2}-4((\mu-\sigma) N \beta-\mu(\gamma+\mu))}\right) \\
&=\frac{1}{2}\left(-\mu R_{v} \pm \sqrt{D_{v}}\right) \\
& \text { dimana } D_{v}=\left(\mu R_{v}\right)^{2}-4((\mu-\sigma) N \beta-\mu(\gamma+\mu)) .
\end{aligned}
$$

Kestabilan titik ekuilibrium bebas penyakit, $J_{E_{b}}$, dapat dilihat dari nilai eigen (3.7), dimana semua nilai eigen akan bernilai riil negatif jika $(\mu-\sigma) N \beta-\mu(\gamma+\mu)<0$ atau $(\mu-\sigma) R_{0}=R_{v}<1$. Artinya, titik ekuilibrium bebas penyakit $E_{b}$ akan stabil asimtotik jika $R_{v}<1$ dan tidak stabil jika $R_{v}>1$.

Kemudian kestabilan dari titik ekuilibrium endemik $E_{b}^{*}$ dapat dilihat dari nilai eigen (3.8) yang bergantung pada nilai di dalam akar, yaitu $D_{v}$. Jika $D_{v}>0$, maka terdapat dua akar riil negatif dengan syarat $\sqrt{D_{v}}<\mu R_{v}$, dan terdapat dua akar riil berbeda tanda dengan syarat $\sqrt{D_{v}}>\mu R_{v}$. Jika $D_{v}<0$, maka terdapat nilai eigen kompleks dengan bagian riilnya negatif. Berdasarkan kondisi tersebut, maka semua nilai eigen dengan bagian riil akan bernilai negatif jika $R_{v}>1$. Artinya, titik ekuilibrium endemik $E_{b}^{*}$ akan stabil asimtotik jika $R_{v}>1$ dan tidak stabil jika $R_{v}<1$.

\subsection{Simulasi Numerik}

Nilai masing-masing parameter pada model (3.1) dan (3.2) diperoleh dengan menggunakan data penyakit Tuberculosis (TBC) di Provinsi Sumatera Barat tahun 2018. Nilai masing-masing parameter yang digunakan adalah sebagai berikut: $N=5382 \mu=2,68 ; \gamma=0,47 ; \beta=0,002 ; \sigma=0,8$; dengan nilai awal $S(0)=$ $2500 ; I(0)=10 ; R(0)=5$.

\subsubsection{Simulasi Model SIR dengan Vaksinasi Konstan}
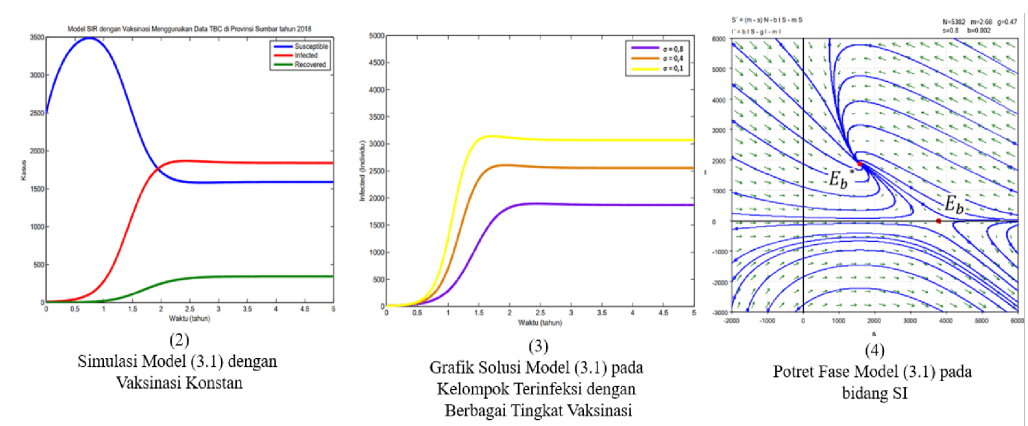

Gambar 2. Simulasi Model (3.1) dengan Vaksinasi Konstan 
Gambar (2) memperlihatkan simulasi pemberian vaksin secara konstan kepada populasi rentan. Pemberian vaksinasi secara konstan sebesar $\sigma=0,8$ membuat jumlah individu yang rentan akan mengalami penurunan dan menekan laju jumlah individu yang terinfeksi. Namun individu yang terinfeksi masih ada di dalam populasi.

Laju perubahan jumlah individu yang terinfeksi dengan beberapa tingkat vaksinasi, yaitu $\sigma 1=0.8, \sigma 2=0.4$ dan $\sigma 3=0.1$, diperlihatkan pada Gambar (3). Dari gambar tersebut terlihat bahwa semakin tinggi tingkat vaksin yang diberikan, semakin kecil jumlah individu yang terinfeksi, begitu sebaliknya.

Titik ekuilibrium bebas penyakit $E_{b}=(3775,4 ; 0 ; 0)$ mempunyai nilai eigen $\lambda_{1}=$ $-2,68, \lambda_{2}=-2,68$, dan $\lambda_{3}=4,4$. Disimpulkan bahwa ketiga nilai eigen tersebut riil dan berbeda tanda, mengakibatkan titik ekuilibrium $E_{b}$ bertipe saddle dan bersifat tidak stabil. Sebaliknya, titik ekulibrium endemik $E_{b}^{*}=(1575 ; 1872,11 ; 328,32)$ mempunyai nilai eigen $\lambda_{1}=-2,68, \lambda_{2,3}=-3,21 \pm 1,22 i$. Disimpulkan bahwa terdapat nilai eigen kompleks dengan bagian riilnya bernilai negatif, berakibatkan titik ekuilibrium $E_{b}^{*}$ bertipe spiral dan bersifat stabil asimtotik.

\subsubsection{Simulasi Model SIR dengan Vaksinasi Berkala}

Dalam mengamati dinamika model $S I R$ dengan pemberian vaksinasi secara berkala, akan diberlakukan tiga strategi pemberian vaksinasi, yaitu [10]: Strategi pertama : pemberian vaksin dilakukan 2 kali setahun; Strategi kedua : pemberian vaksin dilakukan 1 kali setahun; Strategi ketiga : pemberian vaksin dilakukan setiap 2 tahun sekali.

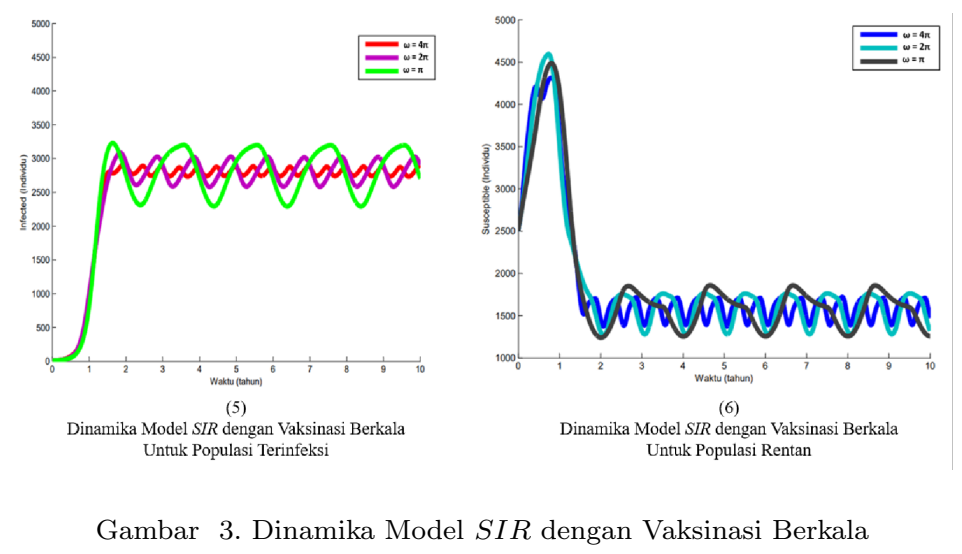

Gambar (5) memperlihatkan perbandingan antara tiga strategi vaksinasi terhadap populasi yang terinfeksi. Strategi pertama vaksinasi dua kali setahun, sedangkan strategi kedua vaksinasi setahun sekali. Akhirnya, strategi ketiga mengusulkan vaksinasi terjadi setiap dua tahun. Perubahan periode vaksinasi tersebut dicapai dengan mengubah nilai $\omega$. Sementara itu, Gambar (6) menunjukkan dinamika populasi yang rentan dengan ketiga strategi vaksinasi tersebut. Dapat dilihat bahwa semakin besar $\omega$, semakin stabil perilaku dinamiknya. 


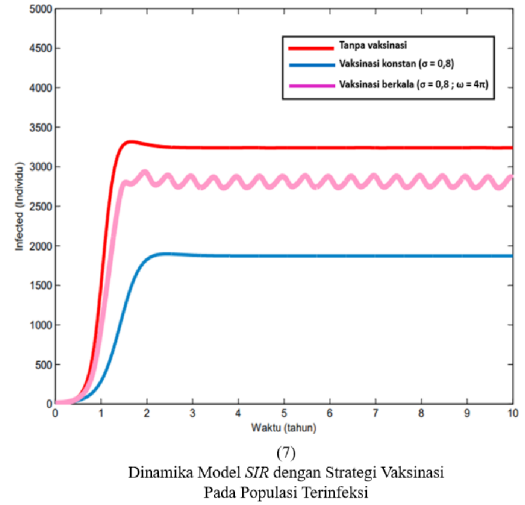

Gambar 4. Dinamika Model SIR dengan Strategi Vaksinasi Pada Populasi Terinfeksi

Dalam Gambar (7) dinamika individu yang terinfeksi disajikan dalam tiga strategi : tanpa pengaruh vaksinasi, dengan vaksinasi yang konstan dan dengan vaksinasi berkala. Terlihat bahwa populasi yang divaksinasi secara konstan cenderung stabil menuju titik ekuilibrium, dengan jumlah individu yang terinfeksi lebih sedikit bila dibandingkan dengan populasi tanpa divaksinasi.

\section{Kesimpulan}

(1) Penelitian ini membahas dinamika model SIR dengan strategi vaksinasi, yaitu vaksinasi konstan dan vaksinasi berkala.

(2) Didefinisikan suatu fungsi vaksinasi, yaitu

$$
\sigma^{*}= \begin{cases}0 & ; \text { jika } \cos (\omega t+\phi) \leq 0 \\ \sigma(\cos (\omega t+\phi)) & ; \text { jika } \cos (\omega t+\phi)>0\end{cases}
$$

(3) Dari analisis kestabilan model yang dikaitkan dengan parameter ambang batas, diperoleh:

- Titik ekuilibrium bebas penyakit $\left(E_{b}\right)$ stabil asimtotik jika $R_{v}<1$ dan sebaliknya tidak stabil jika $R_{v}>1$.

- Titik ekuilibrium endemik $\left(E_{b}^{*}\right)$ stabil asimtotik jika $R_{v}>1$ dan sebaliknya tidak stabil jika $R_{v}<1$.

(4) Hasil analitik telah dikonfimasi dengan hasil numerik yang menggunakan data penyakit TBC di Provinsi Sumatera Barat tahun 2018 dengan menampilkan grafik solusi dan potret fasenya. Pemberlakuan pemberian stategi vaksinasi kepada populasi efektif sebagai pencegahan awal dalam menekan penyebaran penyakit dan menekan laju jumlah individu yang terinfeksi, walaupun individu yang terinfeksi masih ada di dalam populasi. 


\section{Daftar Pustaka}

[1] Bastian, G. 2018. Lectures On Mathematical Modeling of Biological Systems

[2] Dinas Kesehatan Provinsi Sumatera Barat. 2018. Data Kasus TBC di Provinsi Sumbar. Padang : Bidang Pencegahan Penyakit Menular (P2M) Kesehatan Provinsi Sumbar

[3] Finizio, N., G. Ladas. 1998. Persamaan Diferensial Biasa dengan Penerapan Modern Edisi Kedua. Terjemahan Bahasa Indonesia. Jakarta : Erlangga

[4] Hirsch, Morris W., Stephen Smale, dan Robert L. Devaney. 2004. Diferential Equation Dynamical Systems And An Introduction To Chaos Second Edition. Elsevier (USA) : Elsevier Academic Press

[5] Kelley, Waller G. dan Allan C. Peterson. 2010. The Theory of Differential Equation Second Edition. New York : Springer

[6] Kermack, W.O. adn Mackendrick, A.G. 1927. A Contribution Mathematical Theory of Epidemics. Proceedings of the Royal Society of London. Series A. Volume 115, 700-721

[7] Lynch, Stephen. 2007. Dynamical System With Applications Using MATLAB Second Edition. Manchester : Birkhauser

[8] Lynch, Stephen. 2007. Dynamical System With Applications Using Mathematica. Boston : Birkhauser

[9] Peraturan Menteri Kesehatan Republik Indonesia Nomor 67 Tahun 2016 Tentang Penanggulangan Tuberkulosis

[10] Perko, L. 1991. Differential Equations and Dynamical Systems. New York : Springer-Verlag

[11] Prates, D.B., C.,L.T.F. Jardim, L.,A.F.Ferreira. 2016. Vaccination Strategies : A Comparative Study In An Epidemic Scenario. Journal of Physics : Conference Series 738

[12] Tu, Pierre N. V. 1994. Dynamical Systems An Introduction With Applications In Economics and Biology Second Revised And Enlarged Edition. Canada : Springer Verlag 